\title{
Prevenção às DST/Aids e Processos Comunicativos: Estudo de Caso, a Partir do Quadro da Vulnerabilidade
}

\author{
Neide Emy Kurokawa Silva ${ }^{\mathbf{1}}$ \\ Instituto de Estudos em Saúde Coletiva da Universidade Federal do Rio de Janeiro, \\ Rio de Janeiro, Brasil \\ Luzia Aparecida Oliveira \\ Programa Municipal DST/Aids da Secretaria Municipal de Saúde de São Paulo, \\ São Paulo, Brasil
}

\begin{abstract}
Resumo
Introdução. O quadro da vulnerabilidade veio propor não apenas um novo modo de fazer, mas também de pensar as ações de prevenção às doenças sexualmente transmissíveis e aids. Objetivo. Considerando que a sua apreensão ainda representa um desafio às práticas de prevenção, fortemente ancoradas em propostas verticalizadas de educação, o presente artigo discute a experiência de uma estratégia de prevenção por pares, evidenciando as potencialidades, possibilidades e desafios de lidar com a complexidade e dinamicidade desse referencial. Metodologia. A experiência foi tomada como estudo de caso e o material, produzido a partir de relatos e relatórios, recebeu tratamento de natureza hermenêutica. Resultados. Identificaram-se tensionamentos na coordenação da estratégia por instituição governamental, além da própria ideia de "par" e suas relações identitárias. Também foram evidenciados os impasses frente à amplitude das proposições do quadro da vulnerabilidade. Conclusão. Ressalta-se, ao final, a fecundidade do investimento nas dimensões comunicativas da estratégia de prevenção por pares, por meio do enriquecimento dos repertórios argumentativos.
\end{abstract}

Palavras-chave: Aids, prevenção por pares, vulnerabilidade.

\section{STDIAIDS Prevention and Communication Processes: A Case Study in the Context of Vulnerability}

\begin{abstract}
Introduction. The vulnerability in STD/AIDS has proposed not only a new way of dealing with this situation, but also of thinking about sexually transmitted diseases and AIDS prevention strategies. Objective. Since the perception of this vulnerability represents a challenge for prevention practices, strongly based on a verticalization strategy, this paper discusses the experience of a participatory peer education as an STD/AIDS prevention strategy, highlighting the potentialities, possibilities and challenges of dealing with the complexity and dynamism of this reference. Methodology. The experience was taken as a case study and the material produced based on reports received hermeneutic treatment. Results. Tensions were identified in the coordination of the strategy by the governmental institution, as well as
\end{abstract}

Endereço para correspondência: Rua Professor Nehemias Gueiros, 243, apto. 201, Recreio dos Bandeirantes, Rio de Janeiro, RJ, Brasil 22790-030. E-mail: neks@uol.com.br e luzia.ao@uol.com.br

Agradecemos o Núcleo de Estudos e Prevenção em Aids (NEPAIDS), por instigar e apoiar reflexões que valorizam a dupla mão entre experiências práticas e produção de conhecimento. Também ressaltamos a cuidadosa e preciosa revisão do texto realizada pelas companheiras Dulce Ferraz e Maria Ines Battistella Nemes. As autoras trabalharam juntas em todas as etapas de elaboração do manuscrito. 
the very idea of "peer" and its identity relations. The dilemmas represented by the wide range of propositions regarding vulnerability were also highlighted. Conclusion. In conclusion, we stress that investment in the communication dimensions of peer prevention, through the enrichment of argumentative repertoires, was fruitful.

Keywords: Aids, peer prevention, vulnerability.

\section{Prevención a las DST/Sida y Procesos Comunicativos: Estudio de Caso, a Partir del Cuadro de la Vulnerabilidad}

\section{Resumen}

Introducción. El cuadro de la vulnerabilidad vino proponer no sólo un nuevo modo de hacer, pero también de pensar, las acciones de prevención a las enfermedades sexualmente transmisibles y sida. Objetivo. Considerando que su aprehensión aun representa un desafío a las prácticas de prevención, fuertemente apoyadas en propuestas verticales de educación, el presente articulo discute la experiencia de una estrategia de prevención por pares, evidenciando las potencialidades, posibilidades, y desafíos de trabajar con la complexidad y diligencia de ese referencial. Metodología. La experiencia fue tomada como estudio de caso y el material, producido a partir de relatos e informes, recibió tratamiento de naturaleza hermenéutica. Resultados. Identificaron tensiones en la coordinación de la estrategia por institución gubernamental, además de la propia idea de "par" y sus relaciones en comunes. También fueron evidenciados los impases frente a la amplitud de las proposiciones del cuadro de la vulnerabilidad. Conclusión. Se resalta, al final, la fecundidad del a inversión en las dimensiones comunicativas de la estrategia de prevención por pares, por medio del enriquecimiento de los repertorios argumentativos.

Palabras clave: Sida, prevención por pares, vulnerabilidad.

\section{Desafios do Quadro da Vulnerabilidade às Ações de Prevenção às DST/Aids}

Quando da implantação do Programa Nacional de DST e Aids no Brasil, em meados dos anos 1980, a política de prevenção visando ao controle da incidência de novas infecções pelo HIV era voltada para o desenvolvimento de abordagens e metodologias dirigidas à avaliação e à percepção do risco, em particular do comportamento de risco de grupos específicos (Ministério da Saúde, 2005). Logo se perceberam os limitantes de tais abordagens, como o fomento a situações de estigma e discriminação e a necessidade de uma nova formulação conceitual e prática que incorporasse outros referenciais, sensíveis aos diferentes contextos que modelam as possibilidades de prevenção, tendo os direitos humanos como horizonte.

No bojo dessa nova abordagem, a proposição do conceito de "vulnerabilidade", como postulado nos trabalhos de Mann, Tarantola e Netter (1993) e desenvolvido no Brasil a partir dos estudos de Ayres e colaboradores (Ayres, Cala- zans, \& Saletti, 2003; Ayres, França, Calazans, \& Saletti, 2003; Ayres, Freitas, Santos, Saletti, \& França, 2003), renova o foco estritamente individual das ações de prevenção ao HIV, apontando para a importância da articulação desta com as dimensões social e programática. Referido marco teórico traz como exigência que as intervenções levem em conta as diferentes características e demandas de grupos populacionais específicos, bem como os contextos em que estão inseridos, considerando as relações de gênero, as situações de pobreza, de violência, entre outros determinantes das condições de saúde.

A apropriação do quadro da vulnerabilidade como orientador das ações e como horizonte ético e político para as práticas de prevenção amplia e dá luzes para a compreensão dos contextos que modelam diferentes modos de exposição ao HIV, bem como de proteção de cada pessoa ou grupo.

Coerentemente com suas origens, como fruto de uma necessidade identificada e debatida a partir dos desafios práticos impostos com a eclo- 
são da epidemia de aids, o quadro da vulnerabilidade busca captar a dinamicidade dos contextos, procurando construir totalidades compreensivas, "sempre a partir de uma dada perspectiva, limitada e em constante transformação" (Ayres, 2009, p. 17). A abrangência desse tipo de proposta, entretanto, corre o risco de ser confundida como aspiração a uma apreensão totalizante de todos os contextos que podem tornar as pessoas, comunidades ou populações mais suscetíveis à infecção pelo HIV, equívoco esse propício a uma "ampliação paralisante", sobretudo em relação às iniciativas práticas com vistas à prevenção da transmissão do HIV. Nesse sentido, é importante destacar que, "por mais abrangente e exaustivo que seja um estudo de vulnerabilidade, ele jamais poderá ter a pretensão de dar a palavra final sobre o assunto" (Ayres, 2009, p. 17).

O caráter inovador e mesmo revolucionário que o quadro da vulnerabilidade traz para o campo da saúde pressupõe, além do reconhecimento dos horizontes éticos e políticos que promove, um processo de reconstrução das bases das ações de prevenção, ainda fortemente apoiadas nos clássicos pressupostos da educação sanitária.

Para ir de encontro a essa situação, a política nacional de aids tem buscado estratégias que permitam a construção de uma resposta abrangente, por meio da articulação intersetorial, da aproximação e articulação com a sociedade civil organizada e os movimentos sociais (Câmara \& Lima, 2000; Galvão, 2000; Grangeiro, Silva, \& Teixeira, 2009) e do incentivo à construção de práticas inovadoras, sensíveis à multidimensionalidade dos contextos que podem expor ou proteger indivíduos e comunidades da infecção pelo HIV (Ministério da Saúde, 2005).

Ao lado dos avanços nesse sentido, a incorporação do quadro da vulnerabilidade tanto na produção de conhecimento quanto nas práticas de prevenção ainda representa um desafio enquanto uma proposta contra-hegemônica no modo de pensar e fazer prevenção (Ayres, França, et al., 2003; Nichiata, Bertolozzi, Takahashi, \& Fracolli, 2008).

Visando a adensar a compreensão acerca da apreensão do quadro da vulnerabilidade nas ações de prevenção às DST/aids, o presente arti- go pretende deslindar a experiência com uma estratégia de prevenção, apoiada nos pressupostos desse quadro, evidenciando as potencialidades, possibilidades e desafios de lidar com a complexidade e dinamicidade desse referencial.

Nesse sentido, inicialmente, faz-se necessário situar em linhas gerais a estratégia de prevenção por pares e a sua utilização no âmbito das DST/aids, para então explicitar a experiência propriamente dita e o percurso metodológico trilhado para a sua compreensão.

\section{A Estratégia de Prevenção por Pares e suas Possibilidades de Apreensão}

A experiência que inspirou o presente ensaio faz parte de uma iniciativa do Programa Municipal de DST/Aids do município de São Paulo, que a partir de 2001 lançou uma série de projetos de prevenção por pares, visando a aproximar-se de populações específicas, de difícil acesso pelos técnicos dos serviços de saúde.

As intervenções conduzidas por pares podem assumir variados enfoques, sob denominações como tutoria por pares, aconselhamento por pares ou educação por pares. O campo de prevenção ao HIV tem explorado largamente essa última estratégia, sob os mais diversos critérios de afinidade: orientação sexual, identidade de gênero, estilos de vida, idade, profissão, comunidade de moradia, lazer.

A partir dessa ideia e do reconhecimento de que há grupos que estão mais vulneráveis à infecção pelo HIV, além da necessidade de propor tecnologias apropriadas a esses contextos específicos, uma das possibilidades em voga é o trabalho de prevenção intermediado por membros dos próprios grupos, considerando os referidos critérios de afinidade entre os mesmos.

Tanto a eficácia dessa metodologia (Harden, Oakley \& Oliver, 2001) quanto a sua fundamentação em uma teoria específica (Turner \& Shepherd, 1999) não reúnem consenso. Grande parte da literatura, sobretudo a norte-americana, baseada em teorias de matriz cognitivo-comportamentalista, justifica sua aplicação pelo baixo custo; pela oportunidade de oferecer capacitação e benefícios para os envolvidos; pela possibilidade de contatar populações de difícil acesso; 
por considerar os pares como fontes de informações credíveis e aceitáveis; e por tomar os pares como modelos positivos que asseguram um reforço continuado das aprendizagens (Turner \& Shepard, 1999). Ademais, vale destacar uma publicação da UNAIDS, de 1999, que, ao lado das teorias comportamentalistas, menciona a pedagogia de Paulo Freire como uma outra importante abordagem na educação por pares. Num polo menos explorado, destacam-se iniciativas brasileiras que consideram os aspectos socioculturais dos indivíduos, dos grupos e das comunidades em suas intervenções (Ayres et al., 2003c; Calazans, Kiss, Sequeira, Vieira \& França Júnior, 2006; Moreira, Silveira \& Andreoli, 2006).

No campo da prevenção às DST/aids, a proposta de educação por pares tem sido assimilada e disseminada tanto por iniciativas governamentais quanto não governamentais, com diferentes justificativas, pressupostos e metodologias. No Brasil, o Programa Nacional de DST e Aids vem, desde 1996, indicando essa estratégia como uma das possibilidades de intervenção no campo da prevenção (Ministério da Saúde, 1996, 2008), embora haja registros de que essa estratégia tenha se iniciado em meados de 1989, na cidade de Santos, em São Paulo, e em 1995, em Salvador, na Bahia, com foco principalmente nos usuários de drogas injetáveis (Feffermann \& Figueiredo, 2006).

As intervenções feitas pelos próprios pares, em comparação àquelas realizadas por técnicos/profissionais de saúde, podem estar mais próximas das abordagens inspiradas no quadro da vulnerabilidade, ao se aproximarem da noção de emancipação psicossocial (Paiva, 2002), por meio do protagonismo social e da coparticipação dos cidadãos nos processos educativos. Referida perspectiva emancipatória das ações de prevenção busca a produção de respostas sociais capazes de transformar os contextos que ampliam a vulnerabilidade de pessoas e comunidades à infecção pelo HIV, como, por exemplo, a partir do questionamento sobre quais as barreiras para acessar e fazer uso dos insumos de prevenção, sobre a capacidade dos serviços de saúde em atender às suas demandas e, mais do que isso, sobre a mobilização para a garantia desses direitos.

\section{Os Contornos dos Projetos de Prevenção por Pares no Município de São Paulo}

O Programa Municipal de DST/Aids da cidade de São Paulo tem indicado a estratégia de prevenção por pares na cidade desde o final dos anos 1990 e sua implementação tem ocorrido sob a responsabilidade da Rede Municipal Especializada (RME), inicialmente priorizando-se populações que no decorrer da história vinham sendo mais afetadas pela epidemia, ou seja, os usuários de drogas injetáveis, os profissionais do sexo, os homens que fazem sexo com homens e as mulheres. Posteriormente, passaram a ser incluídas as usuárias de silicone, os jovens e os homens heterossexuais ${ }^{2}$.

Cada uma dessas populações mereceu um projeto específico, concebido e coordenado pelo Programa Municipal de DST/Aids de São Paulo, sendo implementado por meio de agentes de prevenção (denominados "pares"), que são formados e acompanhados por técnicos da RME, em conformidade com as demandas específicas de cada região da cidade, disponibilidades, interesses e possibilidades.

Os projetos de prevenção por meio da educação por pares, nesse contexto, prevê ainda a ideia de "campo", cuja delimitação depende da configuração dos locais de concentração e espaços de socialização das populações priorizadas, como, por exemplo, bares, saunas, estádios/campinhos de futebol, salões de beleza etc.

2 Sob a denominação "PRD Sampa" (Projeto de Redução de Danos), o município de São Paulo inaugurou a abordagem "Prevenção por Pares" em 2002, tendo como foco inicial a redução de danos a usuários de drogas injetáveis, com o oferecimento de insumos, como seringas e agulhas descartáveis, água destilada, swab e preservativos. Posteriormente, essa modalidade de prevenção foi estendida a outras populações, como: mulheres, profissionais do sexo, adolescentes, homens que fazem sexo com homens, e foi configurada por meio de projetos específicos com as seguintes denominações, respectivamente: "Elas por Elas"; "Tudo de Bom"; "Plantão Jovem"; e "Cidadania Arco-Íris". Daremos destaque aqui para o Projeto "Elas por Elas", objeto da presente reflexão analítica. 
Após indicação/identificação de uma pessoa pertencente a um dos grupos populacionais abrangidos pelos projetos, com perfil para a atividade, segue-se o trâmite para a vinculação do agente de prevenção ao respectivo projeto. Esse vínculo com o projeto é formalmente caracterizado como "voluntário", mas prevê uma ajuda de custo mensal correspondente a aproximadamente $70 \%$ do salário-mínimo, para cobrir despesas como transporte e alimentação feitas durante o trabalho de campo.

Essa ajuda de custo é depositada em contacorrente, em instituição bancária previamente definida pela Secretaria Municipal de Saúde de São Paulo e, para tanto, o agente deve possuir os requisitos para abertura da referida conta (como comprovação de endereço, documentos pessoais - CPF, carteira de identidade - e não ter pendências com a instituição bancária). A contratação dos agentes se dá por tempo indeterminado, sendo que o desligamento fica condicionado a avaliações dos técnicos responsáveis por cada projeto.

O acompanhamento das atividades é realizado por meio de reuniões periódicas entre agentes de prevenção e técnicos dos serviços de saúde, responsáveis por cada um dos projetos de prevenção por pares, além de supervisões do trabalho de campo.

\section{Proposta Metodológica}

Diante do delineamento das expectativas vislumbradas para a estratégia de prevenção por pares, em especial daquelas que tomam a vulnerabilidade e os direitos humanos como horizontes e indagações sobre as possibilidades práticas de aproximação a referidas expectativas, recorreu-se aos aportes da Teoria da Ação Comunicativa, como tratada em Habermas (1988).

O exame proposto aproxima-se da perspectiva de um estudo de caso, valendo ressaltar, no entanto, a peculiaridade dessa aproximação, posto que não objetiva generalizar os achados da experiência a outras iniciativas de prevenção por pares, mas tão somente, como dito, ressaltar as potencialidades e desafios dessa estratégia ao ter a vulnerabilidade como norte.
O material que deu contornos ao caso a ser examinado foi produzido a partir dos registros rotineiros sobre o conteúdo e impressões levantadas durante as supervisões e intervenções de campo junto às agentes de prevenção, além de relatórios de campo, coletados pelas técnicas responsáveis pelo desenvolvimento do projeto em um ambulatório especializado em DST/aids do município de São Paulo, sem a pretensão inicial de apreendê-lo como objeto de estudo. No entanto, a participação dessas técnicas, autoras do presente trabalho, em outros espaços de estudos e debates sobre vulnerabilidade as incitou a sistematizar a experiência com a finalidade de refletir sobre os limites e possibilidades dessa estratégia em uma situação prática do cotidiano da atenção à saúde.

Trata-se de um empreendimento de compreensão e interpretação que tem como pano de fundo a incorporação de uma proposta de prevenção por meio da educação por pares em um contexto específico, conformado pela unidade de saúde e seus técnicos responsáveis, assim como pela comunidade específica onde o projeto foi realizado, representando uma apropriação particular das autoras que, na ocasião, eram técnicas responsáveis pelos projetos de prevenção desenvolvidos naquela unidade de saúde.

Se para algumas correntes teóricas o "pertencimento" direto das autoras ao contexto e ao objeto em pauta poderia ser tomado como um empecilho metodológico para o estudo, aqui esse "pertencimento" é explorado em suas potencialidades, posto que o fato de serem partícipes diretas do processo permitiu que meandros do cotidiano fossem incorporados ao movimento compreensivo-interpretativo da temática investigada.

O material oriundo dos registros recebeu tratamento de natureza hermenêutica, tomando o processo de interpretação-compreensão como estruturante da experiência da vida e não como procedimento isolado, controlado por procedimentos ou regras (Gadamer, 1997; Schwandt, 2006). 


\section{Resultados e Discussão}

\section{A Implantação de Projeto de Prevenção por Pares em um Ambulatório Especializado em DST/Aids do Município de São Paulo: Vulnerabilidade Social e a Escolha do Campo}

A partir do fenômeno de feminização da epidemia de aids, o projeto "Elas por Elas" tem por objetivo a aproximação das ações de prevenção do público feminino, recorrendo ao trabalho de mulheres que atuam como agentes de prevenção em seus respectivos espaços comunitários.

Como já anunciado, a experiência de prevenção por pares a ser examinada foi desenvolvida por uma equipe de ambulatório especializado em DST/aids do município de São Paulo, especificamente o Projeto "Elas por Elas", no período de 2004 a 2007, em uma comunidade residente em conjunto habitacional popular, localizado na zona Norte da cidade de São Paulo.

O conjunto habitacional eleito localiza-se em uma região central do bairro, próximo a um grande shopping center, com acesso farto de transporte público, serviços de saúde nas proximidades, escolas, creches, organizações não governamentais que atuam socialmente, sobretudo, com crianças e adolescentes, além de uma unidade da polícia civil, o Departamento de Investigações sobre Crime Organizado (DEIC). Embora a construção dos prédios tenha desalojado parte da favela existente na área, não só algumas moradias permaneceram no local, como novas casas proliferaram ao lado do conjunto habitacional com o decorrer do tempo.

Tanto para a escolha do campo quanto para as aproximações iniciais a esse espaço, foram decisivas as informações fornecidas pelas equipes de saúde da família que atuavam na comunidade.

Além do seu perfil de morbidade, marcado pelo número de casos de tuberculose multirresistente e reinfecções por sífilis, a comunidade apresentava importantes características de vulnerabilidade social, que interagia com consumidores do shopping - que davam esmolas ou seduziam meninas nos semáforos; com políticos oportunistas - que faziam promessas e se utilizavam da comunidade para fins eleitorais; com a polícia e o cenário por ela instaurado, incluindo as relações de poder; e com os traficantes - suas ameaças e benefícios.

Especificamente em relação às mulheres, somavam-se especificidades contextuais que poderiam vulnerabilizá-las à infecção pelo HIV, tais como o fato de que muitas mulheres sofriam violência doméstica; estavam envolvidas direta ou indiretamente com o tráfico e consumo de drogas; e realizavam visitas íntimas aos parceiros, em ambiente prisional.

Embora não sejam determinantes por si só, referidas situações podem suscetibilizar os moradores da comunidade à infecção pelo HIV, a depender das possibilidades e dos modos como lidam, por exemplo, com os contextos de violência doméstica ou mesmo de assédio às meninas, nos semáforos. Deve-se também considerar os possíveis suportes que as escolas, os serviços de saúde e as organizações não governamentais podem disponibilizar à comunidade comunidade; $\mathrm{o}$ quanto esta tem condições de participar ou participa dessa iniciativa ou mesmo do quanto consegue reivindicar ou criar novas pautas, diante do conservadorismo do Estado.

Se a escolha do campo se pautasse exclusivamente na região e no acesso a serviços públi$\cos$, certamente a comunidade não seria alvo do projeto, posto que se localiza, como dito, em local privilegiado da região, dando mostras do caráter dinâmico das análises de vulnerabilidade.

Situando os projetos de prevenção por pares no escopo de uma iniciativa de âmbito programático, no caso, desenvolvido por instância governamental, parece pertinente indagar-se sobre suas potencialidades e fragilidades para fazer face às vulnerabilidades da comunidade à infecção pelo HIV.

\section{Problematizando a Condução do Projeto de Prevenção por Pares, por Instância Governamental}

Vale destacar, que não só para o Projeto "Elas por Elas", mas também para o conjunto de projetos de prevenção por pares conduzidos no município de São Paulo, o vínculo dos agentes 
de prevenção ao projeto, por instância governamental, como esperado, prevê diferentes exigências formais, ao envolver dinheiro público.

Uma primeira questão diz respeito ao tipo de vínculo em si, que não é um emprego formal, mas uma relação denominada "voluntária", a partir da qual o agente recebe uma ajuda de custo, devendo cumprir carga horária de 20 horas semanais. É notório que a ajuda de custo tem funcionado como uma, ou mesmo única, fonte de renda familiar e, nesse contexto, os técnicos sentem-se por vezes constrangidos em desligar o agente, ainda que seu desempenho não corresponda às expectativas.

Outro problema, que pode chocar com pressupostos do projeto, refere-se à motivação dos candidatos a participarem da iniciativa, que é muito mais condicionada à ajuda de custo do que propriamente aos compromissos com a prevenção ou com as questões sociais ou da comunidade.

Em terceiro lugar, a necessidade de abertura de uma conta bancária para recebimento da ajuda de custo pressupõe documentação pessoal em ordem e comprovação de endereço, requisitos nem sempre viáveis quando se lida com situações de efetiva exclusão social.

É certo que o vínculo do projeto à instituição governamental implica a necessidade dessas formalizações e, embora possam vulnerabilizar as próprias aspirações da iniciativa, indaga-se se seria o caso de remeter essas iniciativas a outras instâncias mais flexíveis administrativamente

Ao mesmo tempo, mirando-se nas experiências com os agentes comunitários de saúde, ligados à Estratégia de Saúde de Família e que seguem os pressupostos gerais da prevenção por pares, temos que a gestão dos vínculos cabe a organizações sociais, em princípio, com maior flexibilidade administrativa e gerencial que os órgãos governamentais da administração direta. Nem por isso as relações conseguem ser diferentes, na medida em que, embora mutuamente implicados, mais que o vínculo em si, seja com o Estado, seja com organizações sociais, a questão premente é o tipo de discurso que vai sendo assumido pelos agentes: da linguagem dos "pares" para a linguagem "técnica" da saúde.
A esse respeito, passaremos a discutir esse trânsito ou situação por vezes híbrida do agente de prevenção, como um "técnico" ou como um "par".

\section{Problematizando a Ideia de "Par"}

Com o auxílio inicial de agentes comunitários da Estratégia de Saúde da Família, foram selecionadas duas agentes de prevenção para o projeto "Elas por Elas", moradoras da comunidade e que se mostraram interessadas. Embora participassem de algumas atividades na comunidade, como um programa de entrega de leite, reuniões promovidas por representantes da prefeitura para discutir temas pontuais (como a desocupação das favelas vizinhas) e de desfrutarem de certa proximidade com outras mães em espaços como a escola dos filhos ou mesmo o posto de saúde, o conhecimento que as agentes tinham sobre o conjunto habitacional mostrou-se bastante restrito.

Esse relativo desconhecimento sobre a comunidade não pareceu fortuito. Não obstante o fato de residirem há muitos anos no local, subjazia uma resistência das agentes, ainda que velada, em identificarem suas famílias e suas vidas com as dos demais moradores. O desejo de diferenciarem-se dos moradores locais tinha várias origens; entre elas, parecem mais marcantes a necessidade de esquivarem-se do estigma e da discriminação que morar na comunidade suscitava, além de aspirarem a um futuro diferente e melhor para seus filhos, por meio do investimento em atividades oferecidas pela prefeitura à comunidade, como cursos de inglês, balé, judô, abertas à comunidade, mas pouco procuradas por seus moradores.

A compreensão crítica sobre a comunidade não ultrapassava a noção de que morar naquele local poderia significar obstáculo no acesso a emprego e a aspirar outros projetos de vida, já que não havia uma apreensão mais elaborada e crítica acerca das condições de vida dos moradores, dos porquês dessas condições e, principalmente, de algum tipo de mobilização que visasse à transformação das mesmas.

Num primeiro momento, esse distanciamento poderia ser interpretado como distanciamento 
da própria ideia de "par", c omo esvaziamento do requisito de afinidade. Visto sob outro ângulo, é possível dizer que justamente o compartilhamento dessas identidades, em contextos intersubjetivos (Ayres, 2001), permitiu a construção de alteridades que permitiram romper com o que poderia ser chamado de "destino".

Pode-se dizer que as expectativas em torno do agente de prevenção mormente estão relacionadas àquelas correspondentes ao perfil militante, para o qual a "causa coletiva" é muito clara, vindo a sobrepor-se às "causas pessoais". As agentes, ao contrário, compartilhavam do perfil das demais mulheres do conjunto habitacional, e do caráter ordinário de suas apreensões acerca dos seus cotidianos, geralmente pouco ou nada problematizados do ponto de vista crítico argumentativo, inclusive quanto ao encaminhamento das questões, até mesmo as que as atingiam pessoalmente.

Sobre as expectativas em torno do perfil dos agentes, Tomaz (2002), a propósito da Estratégia de Saúde da Família, chama a atenção para a complexificação dessas expectativas - que começa como um elo entre a comunidade e o serviço de saúde para um transformador da realidade social. Para nomear essa tendência, o autor recorre a dois neologismos: 'super-heroização' e 'romantização', referindo-se tanto à quantidade de atribuições remetidas ao agente quanto à ingenuidade de achar que eles possam, isoladamente, promover a transformação social.

Ao discutir a ideia de par, tem-se a dimensão da sua complexidade, posto que sua conformação não se dá objetivamente, nem a priori, como, por exemplo, morar na comunidade, ser líder comunitário ou ser mulher. Ser um par, no caso dos projetos de prevenção, pressupõe uma construção que considera o lugar da moradia, sua história, ser mulher e ao mesmo tempo ser uma pessoa que tem uma pauta a ser tematizada na comunidade. A noção de par é construída nos contextos intersubjetivos conformados entre as agentes, dessas com a comunidade, com o serviço e os discursos de saúde e de prevenção e com os técnicos que coordenam os projetos, entre outras tantas interações possíveis.
Apostando nesse processo de construção, a experiência ensejou uma aproximação propícia ao entendimento entre estas e os serviços de saúde e a comunidade, que será apresentado a seguir.

\section{Contextos de Vulnerabilidade e o Lugar da Prevenção: A Amplitude Paralisante}

Visando a promover outras aproximações das agentes à comunidade e ao mesmo tempo divulgar o projeto de prevenção, propôs-se que elas realizassem uma visita a todas as moradias do conjunto, apresentando-se como vizinhas e agentes de prevenção, falando sobre o projeto e captando impressões sobre os moradores e a comunidade, que eram sistematizadas e levadas às reuniões de supervisão. Além disso, elas ofereciam e disponibilizavam preservativos àqueles que os quisessem.

Os relatos em reuniões de supervisão indicaram a surpresa das agentes com a diversidade da comunidade, entre fatos pitorescos, como a descoberta de um açougue em um dos apartamentos, e as condições de pobreza extrema encontradas em alguns domicílios. Além disso, foram identificadas outras situações importantes para o planejamento de uma ação de prevenção de DST/aids, como comércio sexual, situações de violência, uso de drogas, abandono pelos parceiros, pais ou mesmo filhos, que deixavam idosos à mercê da sorte, falta de acesso a serviços públicos, entre outras.

Ao final do levantamento, por um lado, as agentes comemoravam o fato de que muitos dos moradores receberam bem a visita e ficaram, segundo elas, aliviados em poder compartilhar com alguém suas questões e seus sofrimentos. Por outro, elas sentiam-se impotentes diante da magnitude dos problemas apresentados, suscitando o ímpeto em querer solucioná-los.

Mesmo que inviável, o fato de quererem dar respostas àqueles que lhes confiaram seus problemas indica, ainda que rudimentarmente, a responsabilização e o espírito de solidariedade para com o outro, que apontam importantes características das interações em geral e da vida em comunidade. 
A fragilidade da prontidão em solucionar os problemas residia no modo imediatista, voluntarista e pontual de operar os encaminhamentos, como recorrer a expedientes não formais para a marcação de consultas em unidades de saúde. O diagnóstico acerca da dificuldade de acesso aos serviços de saúde, no entanto, poderia servir de tema a ser discutido coletivamente e, desse modo, encaminhado.

O contato direto com os moradores e suas falas também levaram as agentes a questionarem sobre o lugar e a importância da prevenção às DST/aids diante de contextos tão adversos.

Essa demanda foi objeto de reflexão e debate entre técnicas e agentes, levando não a localizar um ou $o$ lugar para a prevenção, mas situando-a dinamicamente dentro do contexto que se apresentava e indicando a complexidade dessa relação. É justamente "contra uma ampliação paralisante" que Ayres, França, et al. (2003) chamam a atenção, considerando que não se trata de obter um controle de todos os contextos, mas de conseguir perspectivar a prevenção nesses contextos. Os autores sugerem, inclusive, alguns princípios para guiar objetivos e estratégias para a intervenção, que passam pela efetividade, operacionalidade e progressividade, além da democratização radical dessa eleição.

Em suma, não se tratava de abandonar o trabalho de prevenção por considerá-lo pequeno demais diante dos problemas da comunidade, mas de desenvolvê-lo a partir da sua ativa apreensão e análise, posto que muitos deles podem representar dimensões importantes de vulnerabilidade à infecção ao HIV, como a restrição de horizontes e projetos de vida.

\section{Explorando as Dimensões Comunicativas da Prevenção por Pares}

No decorrer do projeto, além das investidas específicas às mulheres, foram criadas diferentes alternativas de aproximação aos moradores, entendendo que, embora voltado para as mulheres, não havia como se furtar do contato com outros públicos, como homens, adolescentes e profissionais do sexo.

Nesse sentido, foram desenvolvidas atividades com diversos temas, como sexualidade, gravidez, prevenção, violência, filhos, preservativos, em reuniões realizadas em diferentes espaços, incluindo as casas de moradoras da comunidade, nas quais as conversas transcorriam durante oficinas de artesanato, todas sempre incluindo atividades para sensibilização sobre preservativos, além da sua disponibilização.

As abordagens das agentes, confirmadas nas supervisões de campo, incorporaram fortemente os aspectos biomédicos acerca da transmissão da doença, mormente reproduzindo um modo tradicional verticalizado do trabalho de prevenção.

Entretanto, à medida que as agentes desenvolviam atividades rotineiras, como a entrega de preservativos em pontos estratégicos - a creche local, a feira livre, o ponto da condução escolar - que serviam de mote para conversas a respeito de aids, DST, prevenção, esse tipo de abordagem tradicional foi dando espaço para a produção de outros tipos de discursos, mais próximos de uma interação dialógica, o que pareceu um dos aspectos centrais e mais perenes do processo.

A (re)aproximação à comunidade e a construção dos sentidos da prevenção com base na realidade daquele espaço possibilitaram a reconfiguração das ações pedagógicas desenvolvidas pelas agentes, promovidas, sobretudo, nos processos de interação com os moradores, para os quais a prevenção também passou a ser reconstruída discursivamente. Para uma reflexão a respeito desse processo recorrer-se-á a um outro aporte teórico, focando nas possibilidades lançadas por uma comunicação baseada na mediação do entendimento linguístico como mecanismo de coordenação da ação pedagógica.

Trata-se de uma breve incursão filosófica aos estudos desenvolvidos por Habermas em sua Teoria da Ação Comunicativa, aqui tomada muito aquém de sua amplitude e complexidade, mas que destacaremos uma vez que essa reflexão filosófica pode nos auxiliar na compreensão das possibilidades de uma comunicação com potencial emancipatório.

Partindo do pressuposto de que propostas educativas orientadas exclusivamente por uma racionalidade cognitivo-instrumental, ao invés de promoverem a emancipação, conduzem a sociedades cada vez mais alienadas, pouco criati- 
vas e acríticas, o que se espera da estratégia e do agente de prevenção por pares não é apenas uma apropriação formal dos conhecimentos técnicos disponibilizados pelos serviços de saúde, por este e sua comunidade. O sentido privilegiado dessa estratégia de prevenção é justamente conseguir trazer ativamente no desenvolvimento desse trabalho um "outro tipo de racionalidade", mais afeta ao mundo vivido, que é base para questões que envolvem, por exemplo, a vivência da sexualidade, ou ao como ela se expressa na vida de pessoas concretas, o que pensam sobre, como agem, quais os sentidos que atribuem às diferentes vivências nesse campo etc.

Habermas, em sua Teoria da Ação Comunicativa ou Teoria do Agir Comunicativo (1988), apresenta-nos um complexo programa com base no giro linguístico (Habermas, 2002, 2004) e na pragmática linguística (Habermas, 1988, 1996) que nos possibilita a compreensão do que denomina de "racionalidade comunicativa", que preside a compreensão dos processos de entendimento intersubjetivo, considerando diferentes tipos de atividades regidas por regras do cotidiano das pessoas.

A racionalidade comunicativa é orientada pelo diálogo, pela argumentação e a interação com possibilidades de entendimento mútuo. É através do diálogo e das interações linguísticas que se expressam as razões e critérios consensuais, no sentido das regras de convivência de uma sociedade. No entanto, são os processos argumentativos que nos fornecem os critérios e os parâmetros racionais para a coordenação das nossas ações (Habermas, 1988, 1996, 2004).

Esse modo de compreensão nos auxilia no entendimento de que para haver mudanças de posições, mais do que a apropriação de informações ou disponibilização de insumos, é necessário fazer emergir repertórios argumentativos que coloquem em perspectiva as possibilidades e impossibilidades de uma ação, com vistas, no nosso caso, à prevenção.

A razão comunicativa habermasiana é essencialmente dialógica e considera a atitude orientada ao entendimento como pertencente ao telos ou à finalidade da linguagem humana. Portanto, diante da prática cotidiana, pôr em relevo as razões de determinada normatividade, significa problematizá-la com vistas à reconstrução de novos critérios ou parâmetros legitimamente validados por uma comunidade linguística.

O desafio colocado pela Teoria da Ação Comunicativa é justamente o registro de como é possível a construção de consensos entre participantes de discursos em que pretensões de validade possam ser problematizadas por todos os envolvidos. Dessa forma, a coordenação comunicativa entre interlocutores se dá através da expectativa de que, se necessário, cada interlocutor poderá justificar suas pretensões de validade através de argumentações válidas. Quando afirmações passam a ser problematizadas pelos integrantes de uma comunidade, seus participantes terão que abandonar as certezas preestabelecidas e ingressar ou desenvolver um tipo de argumentação, sob a forma de discurso.

As pretensões de validade correspondentes a questões cognitivas são problematizadas nos discursos teóricos, e as correspondentes a questões normativas, nos discursos práticos. Nos dois casos os participantes se distanciam do mundo vivido e assumem uma atitude crítico-hipotética de investigação do que antes era visto como não-problemático. Nos dois casos, a argumentação discursiva tem como ponto de partida a suspensão radical da crença na validade do que havia sido afirmado. Ela é posta entre parênteses, até que se conclua, pelo consenso, o processo de discussão discursiva, que pode levar a confirmação (mas também a negação) dos fatos apresentados como verdadeiros, e a justificação (mas também a refutação) das normas apresentadas como justas. (Rouanet, 1990, p. 114)

Desse modo, parece-nos que as ambições apontadas pelo quadro dos direitos humanos e da vulnerabilidade informando as intervenções do campo da prevenção às DST/aids ganham novo colorido, principalmente tratando-se das abordagens entre pares, quando se destaca o modo operante da comunicação como tratado em Habermas.

Mais que resultados diretamente afetos à quantificação de casos de aids, a intervenção 
ancorada na estratégia de prevenção por pares mostrou-se profícua nas suas dimensões comunicativas, de tematização ativa da prevenção, ensejada pela oferta de preservativos nos locais estratégicos e da presença das agentes, que normalmente suscitava algum tipo de debate. Esse debate transitou dos "chavões" (usar camisinha é como chupar bala com papel, por exemplo), para argumentos mais elaborados, a partir daqueles apresentados pelas agentes, que por sua vez foram construídos no diálogo entre o discurso técnico e um discurso significativamente contextualizado. Um exemplo marcante diz respeito às abordagens iniciais das agentes, que em muito se assemelhavam a "aulas" tradicionais, baseadas na transmissão de conhecimentos. Após algum tempo de trabalho na comunidade e a partir do esforço de estabelecer um diálogo com as demais moradoras, as agentes passaram a utilizar outros argumentos, não apenas centrados nos riscos de transmissão do HIV ou nas possíveis consequências da infecção pelo vírus, mas nas suas próprias experiências com o uso do preservativo, que permitia a manutenção da privacidade após as relações sexuais, posto que não tinham que sair de seus quartos para fazer a higiene, evitando os olhares curiosos dos filhos $\mathrm{e}$ demais moradores do pequeno apartamento.

\section{De Volta à Discussão Prática: O que foi Possível se Produzir com a Estratégia de Prevenção por Pares no Projeto "Elas por Elas"}

Entre as possíveis vulnerabilidades suscitadas pelo próprio modo de organização da intervenção, objeto do caso aqui debatido, e as possibilidades de coconstruções de projetos de prevenção que não privilegiem unicamente os seus aspectos técnicos, vislumbraram-se não apenas as possibilidades de apreensão do quadro da vulnerabilidade, mas também as potencialidades e a importância do investimento nas dimensões comunicativas do processo.

Não é possível almejar um projeto que, para além de mudanças comportamentais pontuais, visasse intervir abrangentemente em contextos de vulnerabilidade, contando tão somente com um serviço de saúde, com um número restrito de técnicos e de alguns agentes de prevenção. Lidar com a prevenção às DST/aids de modo dialógico implica reconstruções ou reconfigurações constantes das abordagens com vistas a incluir distintas lógicas e repertórios argumentativos que presidem os diferentes grupos populacionais. Nesses termos, foram as exigências apreendidas durante a aplicação do projeto que levaram a reformulações no estabelecimento de prioridades e no seu curso, ora entre as que se mostravam operacionalmente viáveis, ora entre as que pareciam potencialmente mais efetivas, tendo sempre como horizontes ético e político reforçar e reconhecer as pessoas da comunidade como sujeitos e cidadãos de direitos.

É, de fato, no reconhecimento mútuo que é possível a compreensão e o compartilhamento de valores de realidades particulares de uma dada comunidade, uma importante condição para a realização do trabalho de educação por pares. Este seria um dos pilares do processo de formação desses agentes. Nesse caso, a racionalidade comunicativa busca o entendimento mútuo e pode promover, a partir de experiências sintonizadas com os valores da comunidade, as ações potencialmente inovadoras e mais próximas aos sentidos válidos para a comunidade.

Em outras palavras, parece produtivo destacar a inclusão nas pautas de intervenção dos diferentes discursos da comunidade, de suas estratégias e de seus modos próprios de dar sentidos e significados aos discursos da prevenção, evidenciando as potencialidades das propostas de prevenção por pares alinhadas a um posicionamento político que vise a práticas emancipatórias. A ideia de valorização da comunicação inspirada na teoria habermasiana, nesse sentido, nos auxilia na compreensão de que não há possibilidades de emancipação sem que as questões que afetam as pessoas e grupos possam ser tematizadas, legitimando ou produzindo novos discursos, consensos e entendimentos entre os partícipes.

\section{Conclusão}

Lidar com a prevenção às DST/aids de modo dialógico implica reconstruções e reconfigurações constantes das abordagens, a fim de incluir 
distintas lógicas e repertórios argumentativos que presidem os diferentes grupos populacionais. Nesses termos, foram exigências profícuas durante a aplicação do projeto reformulações nos tipos de intervenções e abordagens que eram possíveis de serem realizadas, tendo sempre como horizontes éticos e políticos reforçar e reconhecer as pessoas da comunidade como sujeitos e cidadãos com direitos.

Entre erros e acertos, entre avanços e retrocessos, mesmo ainda retomando questões conceituais básicas, essa experiência parece-nos sugestiva do quanto uma estratégia, por mais "tecnologizada" que possa se apresentar, carece - se quisermos de fato nos entender com nossos interlocutores - ser reapropriada a cada contexto e a cada ator envolvido no processo. Objetivos, metas, instrumentos não devem ser empecilhos, mas servir como referências para o trabalho, não ofuscando a riqueza das experiências vividas e dos horizontes que se pretende alcançar.

Ainda que não seja possível promover mudanças em contextos de vulnerabilidade mais amplos, é certo que a tematização da questão tem gerado alguns movimentos, fazendo diferença, ao menos, para aqueles diretamente envolvidos nessa empreitada - agentes de prevenção, técnicos dos serviços de saúde e orientadores sociais.

\section{Referências}

Ayres, J. R. C. M. (2001). Sujeito, intersubjetividade e práticas de saúde. Ciência \& Saúde Coletiva, 6(1), 63-72.

Ayres, J. R. C. M. (2009). Organização das ações de atenção à saúde: Modelos e práticas. Saúde e Sociedade, 18(2), 11-23.

Ayres, J. R. C. M., Calazans, G. J., \& Saletti, H. C., Filho. (2003). Adolescência e vulnerabilidade ao HIV/AIDS: Avaliação de uma estratégia de prevenção entre escolares de baixa renda na cidade de São Paulo. Divulgação em Saúde para Debate, (29), 93-114.

Ayres, J. R. C. M., França, I., Jr., Calazans, G. J., \& Saletti, H. C., Filho. (2003). O conceito de vulnerabilidade e as práticas de saúde: Novas perspectivas e desafios. In D. Czeresnia \& C. M. Freitas (Orgs.), Promoção da Saúde: Conceitos, reflexões e tendências (pp. 117-139). Rio de Janeiro, RJ: Fundação Oswaldo Cruz.

Ayres, J. R. C. M., Freitas, A. C., Santos, M. A. S., Saletti, H. C., Filho, \& França, I., Jr. (2003). Adolescência e aids: Avaliação de uma experiência de educação preventiva entre pares. Interface - Comunicação, Saúde, Educação, 7(12), 123-138.

Calazans, G. J., Kiss, L., Cappellini, S., Sequeira, D., Vieira, R. M., \& França, I., Jr. (2006). Plantões jovens: Acolhimento e cuidado por meio da educação entre pares para adolescentes e jovens nos Centros de Testagem e Aconselhamento - CTA. Saúde e Sociedade, 15(1), 22-36.

Câmara, C., \& Lima, R. M. (2000). Histórico das ONGs/Aids e sua contribuição no campo das lutas sociais. Cadernos ABONG: Direitos Humanos, Cidadania e AIDS, 28, 29-74.

Feffermann, M., \& Figueiredo, R. (2006, dez.). Redução de danos como estratégia de prevenção de drogas entre jovens. Boletim do Instituto de Saúde, 40, 37-40.

Gadamer, H. G. (1997). Mistério da saúde. In H. G. Gadamer, O mistério da saúde: O cuidado da saúde e a arte da Medicina (pp. 101-111). Lisboa, Portugal: Edições 70.

Galvão, J. (2000). As respostas das organizações nãogovernamentais brasileiras frente à epidemia de HIV/AIDS. In R. Parker (Org.), Políticas, instituições e AIDS: Enfrentando a epidemia no Brasil (pp. 69-108). Rio de Janeiro, RJ: Jorge Zahar.

Grangeiro, A, Silva, L., \& Teixeira, P. R. (2009). Resposta à aids no Brasil: Contribuições dos movimentos sociais e da reforma sanitária. Revista Panamericana de Salud Publica, 26(1), 87-94.

Habermas, J. (1988). Teoría de la acción comunicativa. Madri, España: Taurus.

Habermas, J. (1996). Racionalidade e comunicação. Lisboa, Portugal: Edições 70.

Habermas, J. (2002). Pensamento pós metafísico: Estudos filosóficos (2. ed.). Rio de Janeiro, RJ: Tempo Brasileiro.

Habermas J. (2004). Verdade e justificação: Ensaios filosóficos. São Paulo, SP: Loyola.

Harden, A., Oakley, A., \& Oliver, S. (2001). Peerdelivered health promotion for young people: A systematic review of different study designs. Health Education Journal, 60, 339-353. 
Mann, J., Tarantola, D., \& Netter, T. (Orgs.). (1993). $A$ aids no mundo. Rio de Janeiro, RJ: RelumeDumará.

Ministério da Saúde. (1996). Manual do multiplicador. Brasília, DF: Autor.

Ministério da Saúde. (2005). Plano estratégico Programa Nacional de DST e Aids. Brasília, DF: Autor.

Ministério da Saúde. (2008). Manual de prevenção das DSTs/HIV/Aids em comunidades populares: Vol. 83. Série manuais. Brasília, DF: Autor.

Moreira, F. G., Silveira, D. X., \& Andreoli, S. N. (2006). Redução de danos do uso indevido de drogas no contexto da escola promotora de saúde. Ciência \& Saúde Coletiva, 11(3), 807-816.

Nichiata, L. Y. I., Bertolozzi, M. R., Takahashi, R. F., \& Fracolli, L. A. (2008). A utilização do conceito "vulnerabilidade" pela enfermagem. Revista Latino-Americana de Enfermagem, 16(5), 923928.

Paiva, V. (2002). Sem mágicas soluções: A prevenção e o cuidado em HIV/AIDS e o processo de emancipação psicossocial. Interface - Comunicação, Saúde, Educação, 6(11), 25-38.
Rouanet, S. P. (1990). Ética e Antropologia. Estudos Avançados, 4(10), 111-150.

Schwandt, T. A. (2006). Três posturas epistemológicas para a investigação qualitativa: Interpretativismo, hermenêutica e construcionismo social. In N. K. Denzin \& Y. S. Lincoln, O planejamento da pesquisa qualitativa: Teorias e abordagens (2. ed., pp. 193-217). Porto Alegre, RS: Bookman.

Tomaz, B. C. T. (2002). O agente de saúde não deve ser um super-herói. Interface - Comunicação, Saúde, Educação, 6(10), 75-94.

Turner, G., \& Shepherd, J. (1999). A method in search of a theory: Peer education and health promotion. Health Education Research: Theory \& Practice, 14(2), 235-247.

Recebido: 26/06/2012

Aceite final: 03/10/2012 